\title{
Erratum to: Self-Control as Mediator and Moderator of the Relationship Between Social Support and Subjective Well-Being Among the Chinese Elderly
}

\author{
Yangjun Tu $\cdot$ Zhi Yang
}

Published online: 4 March 2015

(C) Springer Science+Business Media Dordrecht 2015

\section{Erratum to: Soc Indic Res}

DOI 10.1007/s11205-015-0911-z

Chinese Republic of China should read:

People's Republic of China.

Besides in the Acknowledgments should be added:

This research was also supported by Natural Science Foundation of China 71431008.

The online version of the original article can be found under doi:10.1007/s11205-015-0911-z.

\section{Y. Tu}

Research Institute of Educational Science, Hunan University, Changsha, Hunan, People's Republic of China

e-mail: tuyangjun@163.com; tuyangjun@hnu.edu.cn; tuyangju@umich.edu

Y. Tu

Department of Marketing, Ross School of Business, University of Michigan, Ann Arbor, MI, USA

Z. Yang $(\bowtie)$

School of Business, Hunan University, Changsha, Hunan, People's Republic of China

e-mail: zyng@illinois.edu; yangmkt@126.com 